\title{
Effects of positive airway pressure therapy on cardiovascular and metabolic markers in males with obstructive sleep apnea
}

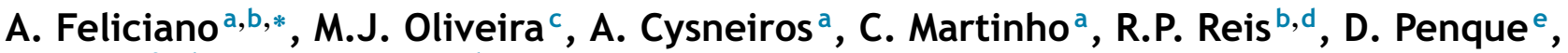 \\ P. Pinto ${ }^{f, g, h}, C$. Bárbara ${ }^{a, g, h}$
}

a Pneumology in Thorax Department, Centro Hospitalar Lisboa Norte, Lisboa, Portugal

b Faculdade de Ciências Médicas, Universidade Nova de Lisboa, Lisboa, Portugal

c Serviço de Pneumologia, Centro Hospitalar de Vila Nova de Gaia e Espinho, EPE, Vila Nova de Gaia, Portugal

d Cardiology Unit, Hospital Pulido Valente, Centro Hospitalar Lisboa Norte, Lisboa, Portugal

e Proteomics Laboratory, Departamento de Genética Humana, Instituto Nacional de Saúde Dr. Ricardo Jorge, Lisboa, Portugal

f Sleep and Non Invasive Ventilation Unit, Thorax Department, Centro Hospitalar Lisboa Norte, Lisboa, Portugal

' Faculdade de Medicina, Universidade de Lisboa, Lisboa, Portugal

${ }^{\mathrm{h}}$ Instituto de Saúde Ambiental, Faculdade de Medicina, Universidade de Lisboa, Lisboa, Portugal

Received 21 October 2016; accepted 25 February 2017

Available online 7 June 2017

\section{KEYWORDS}

Obstructive sleep

apnea;

Lipid metabolism;

Glucose metabolism;

HOMA-IR;

Homocysteine;

PAP

\begin{abstract}
Introduction: Obstructive sleep apnea syndrome (OSAS) is associated with cardiovascular/metabolic complications. Some analytical parameters (homocysteine, glycemic and lipidic profiles) are recognized markers of these consequences. Limited data is available on the association of these markers and OSAS's severity/response to positive airway pressure therapy (PAP).

Material and methods: In this prospective study we analyzed polysomnographic and analytical data of male patients admitted to sleep laboratory. The aim was to evaluate metabolic/cardiovascular markers in snorers and OSAS patients, to relate with sleep parameters and PAP response. One-hundred and three patients were included, and $73(71 \%)$ were OSAS patients. OSAS patients were similar to snorers except for higher body mass index (BMI) and dyslipidemia. Severe OSAS patients showed higher glycemia, HbA1c, insulin, and insulin resistance, and lower HDL cholesterol in comparison to mild-moderate $(p<0.05$, $p<0.05, p<0.001, p<0.001, p<0.05$, respectively). Glycemic profile and triglycerides were slightly correlated with OSAS severity. 46 OSAS patients were submitted to 6 months of PAP,
\end{abstract}

\footnotetext{
* Corresponding author.

E-mail address: amelia.feliciano@chln.min-saude.pt (A. Feliciano).
} 
with a statistical decrease in mean values of homocysteine, glycemia, total and LDL cholesterol $(p<0.05, p<0.05, p<0.05$, respectively), and in glycemia and LDL cholesterol in severe group only ( $p<0.05, p<0.05$, respectively).

Results: This study demonstrated an association between glucose metabolism parameters and triglycerides with OSAS severity underlying the complexity of the process leading to cardiovascular/metabolic complications in this disorder. Moreover, homocysteine, glycemic and lipidic profiles changed significantly after 6 months of PAP therapy in OSAS, supporting its cardiovascular and metabolic protective effect.

Conclusion: Our study has reinforced the importance of analytical cardiovascular/metabolic evaluation as complementary tool of diagnosis/treatment response in OSAS.

(c) 2017 Sociedade Portuguesa de Pneumologia. Published by Elsevier España, S.L.U. This is an open access article under the CC BY-NC-ND license (http://creativecommons.org/licenses/bync-nd/4.0/).

\section{Introduction}

Obstructive sleep apnea syndrome (OSAS) is a common sleep and chronic respiratory disorder, ${ }^{1,2}$ associated with cardiovascular $^{3-5}$ and metabolic (such as obesity, ${ }^{6}$ dyslipidemia $^{7}$ and type 2 diabetes) ${ }^{8}$ complications. It has been difficult to determine if these are due to OSAS or to associated risk factors. Sleep fragmentation and intermittent hypoxia are some mechanisms contributing to OSAS complications, 9,10 which improve with positive airway pressure treatment (PAP). However, the impact of PAP on other mechanisms involved is still not well characterized. Some oxidative stress biomarkers have been associated to OSAS morbidity. ${ }^{11}$ Still controversy remains regarding the best diagnostic/prognostic marker. An example is homocysteine (Hcy), which is considered a "promising" marker. ${ }^{12}$ Hcy is an intermediate product in the biosynthesis of methionine and cysteine, ${ }^{13}$ and is determinant of the methylation cycle. ${ }^{14}$ Hcy levels in adults follow a circadian variation, ${ }^{15}$ being lower in the morning. Studies reported $\mathrm{Hcy}$ as an independent risk factor for atherosclerosis, ${ }^{16,17}$ cerebral, and cardiovascular diseases (CVD), ${ }^{13,18-24}$ being related with their prognosis. ${ }^{18}$ The proposed mechanisms are its adverse effects on vascular structure and function, ${ }^{25}$ hypercoagulability state, ${ }^{23}$ and depletion of nitric oxide. ${ }^{26}$ Moreover, dyslipidemia, diabetes, cancer, renal, and thyroid dysfunction ${ }^{13,23}$ are associated with elevated Hcy. Also, older age, male gender, various drugs, tobacco/coffee/alcohol, and vitamins deficiency. ${ }^{13,23}$ Hcy has been proposed as an OSAS biomarker regarding its relationship with CVD. Studies show higher levels of Hcy in OSAS with ${ }^{27-30}$ or without ${ }^{31,32}$ pre-existing cardiac disease. Moreover there are contradictory studies reporting the effect of PAP on Hcy levels. ${ }^{29,33-37}$

The aim of this study was to analyze Hcy levels in snorers and OSAS patients, its correlation with OSAS severity, and response to PAP. Additionally, glycemic and lipid parameters were also evaluated.

\section{Material and methods}

This prospective study included one hundred three consecutive male subjects with suspicion of OSAS, who were evaluated at a Sleep Clinic. Demographic data included age, body mass index (BMI), Epworth sleepiness scale, and medical history. Exclusion criteria were female gender (to avoid hormonal influence), other sleep disorders, neuromuscular, renal, and thyroid disease, heart failure, cancer, acute disease, and previous PAP.

All patients underwent an overnight polysomnography (PSG) using Embla S7000 System (Embla, USA) with a technician monitoring. Sleep recording and events were manually analyzed according to standard criteria. ${ }^{38}$ The respiratory disturbance index (RDI), oxygen desaturation index (ODI), percentage of time with saturation under $90 \%$ (T90) and lowest oxygen saturation $\left(\mathrm{SpO}_{2}\right)$ were calculated. Based on $\mathrm{RDI} \geq 5$ obstructive events/h of sleep, patients were diagnosed as OSAS $(n=73)$ and grouped into mild (RDI 5-14.9), moderate (RDI 15-29.9), and severe (RDI $\geq 30$ ). Later, in pre/post OSAS treatment analysis, mild and moderate patients were combined $(\mathrm{RDI}<30)$, in order to evaluate the extreme of disease spectrum.

To calculate the sample size we focused in the main objective, that is Hcy analysis before/after PAP treatment. The sample size was calculated with PS software, version 3.1.2. It was planned a study of a continuous response variable from matched pairs of study subjects. Prior data indicated that the difference in the response of matched pairs was normally distributed with standard deviation 2 . If the true difference in the mean response of matched pairs is 0.95 , the sample size need to be of 37 pairs of subjects to be able to reject the null hypothesis that this response difference is zero with probability (power) 0.8 (i.e. beta 0.20 ). The type I error probability associated with this test of this null hypothesis is 0.05 (i.e. alfa 0.05).

According to criteria, ${ }^{39}$ PAP therapy with automatic devices (S9, Resmed, Australia) was prescribed for 46 patients in severe disease or in disease of any severity when associated with excessive diurnal sleepiness and/or cardio/cerebrovascular complications. These patients were evaluated at six months for compliance registration. As described, ${ }^{41}$ more than $4 \mathrm{~h}$ use/night for at least $70 \%$ of nights was considered as acceptable compliance. After PAP initiation, no more indications (excluding healthy lifestyle) were given, assuming a real life scenario.

Venous blood samples were collected after PSG and a 12-h fasting period, into EDTA-coated polypropylene tubes. At six months of PAP a second morning blood sample was collected. The collected blood was processed between 1 and $2 \mathrm{~h}$ to determine Hcy (chemiluminescence 
(CLIA), ADVIA Centaur xp, Siemens). Additionally, parameters of glycemic profile were determined, such as glucose (Enzyme UV Hexoquinase - ADVIA 2400 Siemens), haemoglobin A1c (HbA1c) (HPLC - Variant II BioRad), insulin (chemiluminescence (CLIA), ADVIA Centaur xp, Siemens) and insulin resistance (calculated by homeostatic model assessment of insulin resistance - HOMA-IR). Parameters of lipid profile were, also, determined such as total cholesterol (CHOD-PAP (enzymatic colorimetric) ADVIA 2400, Siemens), low-density lipoprotein (LDL) cholesterol (by calculation), high-density lipoprotein (HDL) cholesterol (HDL Plus 2nd generation elimination/catalase ADVIA 2400, Siemens), and triglycerides (Enzymatic colorimetric (GPO) ADVIA 2400, Siemens). The HOMA-IR was determined by the product between fasting plasma glucose and insulin concentration, which has a reasonable linear correlation with the gold standard of insulin resistance measurement (hyperinsulinemic-euglycemic clamp). ${ }^{40}$

All subjects underwent restriction of alcohol, tea, coffee, chocolate, beetroot, banana, avocado, tomato, plum, pineapple, kiwi, orange, nut, hazelnut, vanilla candies, and confectionery during the three days prior to PSG. Patients underwent $24 \mathrm{~h}$ urine collection (into a hydrochloric acid container and stored at $4^{\circ} \mathrm{C}$ ) for catecholamines determination (adrenaline, nor-adrenaline, and dopamine) (HPLC BioRad).

The study protocol was approved by the local ethics committees and all patients gave written informed consent.

Statistical analyses were performed using SPSS for windows software (SPSS 20 Inc., Chicago, IL, USA). All variables were tested for normality of the distribution using Kolmogorov-Smirnov test. Continuous variables with normal distributions were expressed as means \pm standard deviation (SD) and categorical variables in numbers (percentages). Pearson's analysis was performed for correlations between parametric variables. Independent-samples $T$-test was used for comparisons between independent groups for values that were normally distributed and paired-samples $T$-test was used to compare variables normally distributed before and after PAP treatment. Categorical variables were compared using $X^{2}$ test. Results were considered statistically significant when $p$ value was $<0.05$.

\section{Results}

Clinical and analytical evaluation of snorers and OSAS patients are shown in Table 1. There were no statistically significant differences regarding demographic and analytical parameters. Instead, the existence of known dyslipidemia and BMI were higher in OSAS patients $(p<0.001, p=0.001$, respectively). HOMA-IR, total cholesterol, and urinary noradrenaline were higher than normal range in OSAS patients and Hcy was higher than normal range in both groups.

Concerning OSAS patients, there were no statistically differences between mild-moderate $(46,63 \%)$ and severe $(27,37 \%)$ regarding demographic parameters. Instead, dyslipidemia and BMI were higher in severe OSAS patients $(p<0.05, p<0.001$, respectively). Glycemia, $\mathrm{HbA} 1 \mathrm{c}$, insulin, and HOMA-IR were higher and HDL cholesterol was lower in severe group $(p<0.05, p<0.05, p<0.001, p<0.001, p<0.05$, respectively). Moreover, HbA1c, HOMA-IR, triglycerides, and urinary catecholamines were higher than normal range in severe OSAS patients and total cholesterol and Hcy in both groups.

Some metabolic parameters were slightly correlated with OSAS severity. Glycemia, HbA1c, and triglycerides were positively correlated with RDI ( $p<0.05$, Pearson correlation). Glycemia and HbA1c were negatively correlated with lowest $\mathrm{SpO}_{2}(p<0.05$, Pearson correlation). Instead, insulin and HOMA-IR were positively correlated with RDI, T90, and ODI $(p<0.001$, Pearson correlation) and negatively correlated with lowest $\mathrm{SpO}_{2}(p<0.001)$ (Table 2$)$.

Clinical and analytical evaluation of OSAS treatment patients are shown in Tables 1 and 3. 46 OSAS patients underwent PAP (22 (48\%) were mild-moderate and 24 (52\%) were severe). Patients showed a mean compliance of $4.37 \mathrm{~h} /$ night. Additionally in PAP follow up, weight and smoking habits were always asked and there were no changes in both parameters. After six months of treatment, OSAS patients showed a statistical decrease in Hcy, glycemia, total and LDL cholesterol $(p<0.05)$ (Table 3$)$. Instead, in severe OSAS only glycemia and LDL cholesterol showed a significant reduction $(p<0.05)$.

\section{Discussion}

This study showed after six months of PAP, homocysteine, glycemia, total and LDL cholesterol decrease in OSAS patients pointing to cardiovascular/metabolic protective role of this treatment.

In our study, Hcy was similar in snorers and OSAS patients, and also in different OSAS severities, although being higher than normal range. Hcy is an emerging independent risk factor for CVD, but it is not clear its association with OSAS. Both smoking and obesity may affect Hcy levels, ${ }^{42-47}$ which could be confounders in the association with CVD. In this study, smoking habits and prevalence of CVD were similar between snorers and OSAS patients, and between different levels of OSAS severity. Concerning obesity, snorers and OSAS patients were obese, still OSAS patients presented a higher $\mathrm{BMI}$, which could influence the Hcy levels. The presence of obesity even in snorers is probably responsible for OSAS suspicion and referral to sleep clinic. ${ }^{48}$ Also, several diseases such as dyslipidemia ${ }^{13,23}$ are associated with elevated levels of Hcy, and this disease was more prevalent in OSAS patients.

A meta-analysis (432 subjects) showed higher Hcy levels in OSAS than in controls, ${ }^{49}$ especially when $\mathrm{BMI} \geq 30$, age $<50$ years, and severe OSAS. Other authors ${ }^{50,51}$ also reported higher Hcy levels in severe OSAS. A recent study reported higher Hcy levels in patients with coronary artery disease, with OSAS and with both diseases, ${ }^{30}$ and the highest values for Hcy were observed in the latter group. Further, there was no correlation between Hcy levels and oxygen desaturation, as showed in the present study. Contrary to these results, some studies did not report increased levels of Hcy in OSAS patients with ${ }^{34,35}$ or without associated CVD. ${ }^{28,29,36}$ Although, Hcy was not correlated with sleep parameters, in OSAS patients it decreased for normal values after 6 months of PAP therapy, which may suggest that its levels could in part be related with OSAS. These results are similar to a study of 12 OSAS patients with CVD, which reported a reduction in Hcy levels after PAP therapy. ${ }^{33}$ This behaviour 
Table 1 Initial evaluation of study participants: demographics, comorbidities, polysomnography data, glycemic and lipidic profiles, homocysteine, and urinary catecholamines (BMI: body mass index; EPW: Epworth sleepiness scale; LDL: low-density lipoprotein; HDL: high-density lipoprotein; HOMA-IR: homeostasis model assessment; OSAS: obstructive sleep apnea syndrome; RDI: respiratory disturbance index; SD: standard deviation; T90: desaturation time under $90 \%$; U: urine).

\begin{tabular}{|c|c|c|c|c|c|c|c|c|c|c|}
\hline & Total & Snorers & OSAS & $\begin{array}{l}\text { Snorers vs. } \\
\text { OSAS }(p)\end{array}$ & $\begin{array}{l}\text { Mild-Mod } \\
\text { OSAS }\end{array}$ & Severe OSAS & $\begin{array}{l}\text { Mild-Mod vs. } \\
\text { Severe OSAS } \\
(p)\end{array}$ & $\begin{array}{l}\text { Mild-Mod } \\
\text { OSAS before } \\
\text { PAP }\end{array}$ & $\begin{array}{l}\text { Severe OSAS } \\
\text { before PAP }\end{array}$ & $\begin{array}{l}\text { Mild-Mod vs. } \\
\text { severe OSAS } \\
\text { before PAP } \\
(p)\end{array}$ \\
\hline & $N=103$ & $N=30$ & $N=73$ & & $N=46$ & $N=27$ & & $N=22$ & $N=24$ & \\
\hline $\begin{array}{l}\text { Age (years) } \\
\quad \text { (media/SD) }\end{array}$ & $46 / 8$ & $45 / 10$ & $46 / 8$ & 0.354 & $46 / 8$ & $47 / 7$ & 0.737 & $47 / 9$ & $47 / 7$ & 0.931 \\
\hline Smoking history (n/\%) & $69 / 67.0$ & $21 / 70.0$ & $48 / 65.8$ & 0.681 & $29 / 63.0$ & $19 / 70.4$ & 0.531 & $14 / 63.6$ & $17 / 70.8$ & 0.612 \\
\hline $\begin{array}{l}\text { Alcohol consumption } \\
(n / \%)\end{array}$ & $66 / 64.1$ & $15 / 50.0$ & $51 / 69.9$ & 0.057 & $30 / 65.2$ & $21 / 77.8$ & 0.265 & $15 / 68.2$ & $18 / 75.0$ & 0.617 \\
\hline $\begin{array}{l}\text { BMI }\left(\mathrm{kg} / \mathrm{m}^{2}\right) \\
\quad(\text { media/SD) }\end{array}$ & $29.4 / 3.8$ & $27.4 / 3.3$ & $30.2 / 3.7$ & 0.001 & $28.9 / 3.0$ & $32.3 / 3.8$ & $<0.001$ & $29.4 / 2.4$ & $32.0 / 3.7$ & 0.006 \\
\hline Cardiac disease $(n / \%)$ & $55 / 53.4$ & $13 / 43.3$ & $42 / 57.5$ & 0.193 & $23 / 50.0$ & $19 / 70.4$ & 0.092 & $12 / 54.5$ & $17 / 70.8$ & 0.263 \\
\hline $\begin{array}{l}\text { Respiratory disease } \\
(n / \%)\end{array}$ & $15 / 14.6$ & $2 / 6.7$ & $13 / 17.8$ & 0.188 & $7 / 15.2$ & $6 / 22.2$ & 0.571 & $3 / 13.6$ & $6 / 25.0$ & 0.382 \\
\hline Dyslipidemia (n/\%) & $49 / 47.6$ & $4 / 13.3$ & $45 / 61.6$ & $<0.001$ & $22 / 47.8$ & $23 / 85.2$ & 0.026 & $10 / 45.5$ & $20 / 83.3$ & 0.030 \\
\hline Diabetes $(n / \%)$ & $7 / 6.8$ & $1 / 3.3$ & $6 / 8.2$ & 0.374 & $2 / 4.3$ & $4 / 14.8$ & 0.115 & $0 / 0$ & $3 / 12.5$ & 0.099 \\
\hline EPW scale (media/SD) & $9.5 / 4.8$ & $9.3 / 5.1$ & $9.5 / 4.7$ & 0.843 & $9.7 / 4.7$ & $9.2 / 4.8$ & 0.694 & $11.7 / 4.1$ & $9.5 / 5.0$ & 0.103 \\
\hline $\begin{array}{l}\text { RDI (events/h) } \\
\quad(\text { media/SD) }\end{array}$ & $20.4 / 23.3$ & $2.8 / 1.3$ & $27.6 / 24.2$ & $<0.001$ & $11.9 / 6.1$ & $54.3 / 19.5$ & $<0.001$ & $12.2 / 6.2$ & $55.0 / 19.3$ & $<0.001$ \\
\hline T90 (\%) (media/SD) & $5.6 / 13.2$ & $1.6 / 8.1$ & $7.2 / 14.5$ & 0.047 & $1.0 / 2.3$ & $17.9 / 19.6$ & $<0.001$ & $1.2 / 2.0$ & $16.4 / 18.2$ & $<0.001$ \\
\hline $\begin{array}{l}\text { Sleep efficiency (\%) } \\
\text { (media/SD) }\end{array}$ & $79.2 / 14.4$ & $77.3 / 14.4$ & $79.1 / 14.5$ & 0.407 & $80.4 / 14.7$ & $79.1 / 14.0$ & 0.703 & $75.2 / 18.6$ & $77.2 / 13.8$ & 0.675 \\
\hline $\begin{array}{l}\text { Lowest SpO2 (\%) } \\
\text { (media/SD) }\end{array}$ & $84.1 / 7.5$ & $88.5 / 4.6$ & $82.3 / 7.7$ & $<0.001$ & $85.3 / 5.4$ & $77.1 / 8.3$ & $<0.001$ & $83.3 / 6.6$ & $77.7 / 7.8$ & 0.012 \\
\hline $\begin{array}{l}\text { ODI } \\
\text { (dessaturations/h) } \\
\text { (media/SD) }\end{array}$ & $16.8 / 22.5$ & $2.2 / 2.9$ & $22.8 / 24.2$ & $<0.001$ & $8.1 / 5.7$ & $47.8 / 23.2$ & $<0.001$ & $8.9 / 6.0$ & $48.1 / 23.8$ & $<0.001$ \\
\hline $\begin{array}{l}\text { Glucose }(\mathrm{mg} / \mathrm{dL}) \\
\text { (media/SD) }\end{array}$ & $101.0 / 25.8$ & $101.2 / 31.3$ & $100.9 / 23.4$ & 0.951 & $95.9 / 17.2$ & $109.4 / 29.8$ & 0.017 & $97.3 / 20.2$ & $109.4 / 31.0$ & 0.128 \\
\hline $\begin{array}{l}\text { Glycosylated } \\
\text { haemoglobin (\%) } \\
\text { (media/SD) }\end{array}$ & $5.8 / 0.8$ & $5.8 / 1.0$ & $5.8 / 0.8$ & 0.957 & $5.6 / 0.5$ & $6.1 / 1.0$ & 0.012 & $5.6 / 0.7$ & $6.2 / 1.0$ & 0.036 \\
\hline $\begin{array}{l}\text { Insulin }(\mathrm{mU} / \mathrm{L}) \\
\quad(\text { media/SD) }\end{array}$ & $14.7 / 8.6$ & $12.7 / 6.8$ & $15.5 / 9.1$ & 0.124 & $12.4 / 6.8$ & $20.9 / 10.1$ & $<0.001$ & $11.3 / 5.0$ & $20.8 / 10.4$ & $<0.001$ \\
\hline HOMA-IR (media/SD) & $3.8 / 2.8$ & $3.3 / 2.8$ & $4.0 / 2.8$ & 0.241 & $3.1 / 2.2$ & $5.7 / 2.9$ & $<0.001$ & $2.8 / 1.7$ & $5.6 / 2.9$ & $<0.001$ \\
\hline
\end{tabular}


Table 1 (Continued)

\begin{tabular}{|c|c|c|c|c|c|c|c|c|c|c|}
\hline & Total & Snorers & OSAS & $\begin{array}{l}\text { Snorers vs. } \\
\text { OSAS }(p)\end{array}$ & $\begin{array}{l}\text { Mild-Mod } \\
\text { OSAS }\end{array}$ & Severe OSAS & $\begin{array}{l}\text { Mild-Mod vs. } \\
\text { Severe OSAS } \\
(p)\end{array}$ & $\begin{array}{l}\text { Mild-Mod } \\
\text { OSAS before } \\
\text { PAP }\end{array}$ & $\begin{array}{l}\text { Severe OSAS } \\
\text { before PAP }\end{array}$ & $\begin{array}{l}\text { Mild-Mod vs. } \\
\text { severe OSAS } \\
\text { before PAP } \\
(p)\end{array}$ \\
\hline & $N=103$ & $N=30$ & $N=73$ & & $N=46$ & $N=27$ & & $N=22$ & $N=24$ & \\
\hline $\begin{array}{l}\text { Total cholesterol } \\
\qquad(\mathrm{mg} / \mathrm{dL}) \\
\text { (media/SD) }\end{array}$ & $192.1 / 37.7$ & $185.9 / 41.3$ & $194.6 / 36.1$ & 0.290 & $194.2 / 38.4$ & $195.3 / 32.4$ & 0.092 & $191.6 / 42.7$ & $193.7 / 30.0$ & 0.852 \\
\hline $\begin{array}{l}\text { LDL cholesterol } \\
\qquad(\mathrm{mg} / \mathrm{dL}) \\
\text { (media/SD) }\end{array}$ & $121.0 / 31.6$ & $117.2 / 33.4$ & $122.6 / 30.9$ & 0.435 & $122.1 / 30.6$ & $123.5 / 32.0$ & 0.854 & $123.8 / 32.6$ & $122.0 / 28.2$ & 0.850 \\
\hline $\begin{array}{l}\text { HDL cholesterol } \\
\text { (mg/dL) } \\
\text { (media/SD) }\end{array}$ & $44.7 / 10.1$ & $44.7 / 10.4$ & $44.7 / 10.0$ & 1.000 & $46.8 / 11.3$ & $41.2 / 6.0$ & 0.019 & $44.6 / 12.3$ & $41.0 / 5.5$ & 0.190 \\
\hline $\begin{array}{l}\text { Triglycerides (mg/dL) } \\
\text { (media/SD) }\end{array}$ & $134.6 / 79.3$ & $121.0 / 68.0$ & $140.2 / 83.3$ & 0.265 & $128.8 / 79.4$ & $159.7 / 87.6$ & 0.126 & $120.0 / 57.1$ & $160.7 / 88.7$ & 0.074 \\
\hline $\begin{array}{l}\text { Homocysteine } \\
(\mu \mathrm{mol} / \mathrm{L})\end{array}$ & $15.2 / 3.4$ & $14.7 / 3.3$ & $15.3 / 3.5$ & 0.399 & $15.3 / 3.8$ & $15.3 / 2.9$ & 0.997 & $14.9 / 3.1$ & $15.6 / 2.6$ & 0.436 \\
\hline $\begin{array}{l}\text { Adrenaline }(\mu \mathrm{g} / 24 \mathrm{~h} \\
\text { U) (media/SD) }\end{array}$ & $19.9 / 15.5$ & $17.7 / 16.3$ & $20.8 / 54.2$ & 0.765 & $13.8 / 12.3$ & $32.7 / 87.4$ & 0.152 & $14.2 / 13.1$ & $34.7 / 92.6$ & 0.308 \\
\hline $\begin{array}{c}\text { Noradrenaline } \\
\qquad(\mu \mathrm{g} / 24 \mathrm{~h} \mathrm{U}) \\
(\text { media/SD) }\end{array}$ & $85.7 / 180.4$ & $64.6 / 28.1$ & $94.3 / 213.4$ & 0.45 & $63.1 / 35.5$ & $147.5 / 345.4$ & 0.103 & $62.0 / 35.4$ & $149.7 / 365.9$ & 0.269 \\
\hline $\begin{array}{l}\text { Dopamine }(\mu \mathrm{g} / 24 \mathrm{~h} \mathrm{U}) \\
\quad(\text { media/SD) }\end{array}$ & $434.6 / 771.5$ & $373.9 / 197.0$ & $459.5 / 908.5$ & 0.611 & $340.9 / 202.1$ & $661.5 / 1465.5$ & 0.147 & $334.7 / 220.4$ & $657.2 / 1550.0$ & 0.339 \\
\hline
\end{tabular}


Table 2 Correlation between variables of polysomnography and glycemic and lipidic profiles, homocysteine, and urinary catecholamines (LDL: low-density lipoprotein; HDL: high-density lipoprotein; HOMA-IR: homeostasis model assessment; ODI: oxygen desaturation index; RDI: respiratory disturbance index; T90: desaturation time under 90\%; U: urine).

\begin{tabular}{|c|c|c|c|c|c|c|c|c|}
\hline & \multicolumn{2}{|c|}{ Glucose (mg/dL) } & \multicolumn{2}{|c|}{ Glycosylated haemoglobin (\%) } & \multicolumn{2}{|c|}{ Insulin $(\mathrm{mU} / \mathrm{L})$} & \multicolumn{2}{|c|}{ HOMA-IR } \\
\hline & $r$ & $p$ & $r$ & $p$ & $r$ & $p$ & $r$ & $p$ \\
\hline RDI (events/h) & 0.217 & 0.027 & 0.217 & 0.028 & 0.423 & $<0.001$ & 0.382 & $<0.001$ \\
\hline T90 (\%) & 0.179 & 0.071 & 0.121 & 0.224 & 0.342 & $<0.001$ & 0.331 & 0.001 \\
\hline Sleep efficiency (\%) & 0.01 & 0.923 & 0.018 & 0.857 & 0.009 & 0.925 & 0.061 & 0.539 \\
\hline Lowest SpO2 (\%) & 0.264 & 0.007 & 0.242 & 0.014 & 0.321 & 0.001 & 0.372 & $<0.001$ \\
\hline ODI (dessaturations/h) & 0.181 & 0.068 & 0.172 & 0.083 & 0.428 & $<0.001$ & 0.384 & $<0.001$ \\
\hline
\end{tabular}

Total cholesterol $(\mathrm{mg} / \mathrm{dL}) \quad \mathrm{LDL}$ cholesterol $(\mathrm{mg} / \mathrm{dL}) \quad \mathrm{HDL}$ cholesterol $(\mathrm{mg} / \mathrm{dL}) \quad$ Triglycerides $(\mathrm{mg} / \mathrm{dL})$

\begin{tabular}{|c|c|c|c|c|c|c|c|c|}
\hline & & & & & & \\
\hline & $r$ & $p$ & $r$ & $p$ & $r$ & $p$ & $r$ & $p$ \\
\hline RDI (events/h) & 0.087 & 0.385 & 0.056 & 0.577 & 0.123 & 0.215 & 0.205 & 0.038 \\
\hline T90 (\%) & 0.133 & 0.180 & 0.111 & 0.267 & 0.021 & 0.833 & 0.154 & 0.122 \\
\hline Sleep efficiency (\%) & 0.115 & 0.246 & 0.126 & 0.206 & 0.012 & 0.908 & 0.002 & 0.986 \\
\hline Lowest SpO2 (\%) & 0.110 & 0.269 & 0.079 & 0.432 & 0.008 & 0.937 & 0.141 & 0.155 \\
\hline ODI (dessaturations/h) & 0.094 & 0.343 & 0.081 & 0.421 & 0.119 & 0.229 & 0.175 & 0.076 \\
\hline
\end{tabular}

\begin{tabular}{|c|c|c|c|c|c|c|c|c|}
\hline & \multicolumn{2}{|c|}{ Homocysteine ( $\mu \mathrm{mol} / \mathrm{L})$} & \multicolumn{2}{|c|}{ Adrenaline ( $\mu \mathrm{g} / 24 \mathrm{~h} U)$} & \multicolumn{2}{|c|}{ Noradrenaline $(\mu \mathrm{g} / 24 \mathrm{~h} \mathrm{U})$} & \multicolumn{2}{|c|}{ Dopamine $(\mu \mathrm{g} / 24 \mathrm{~h} \mathrm{U})$} \\
\hline & $r$ & $p$ & $r$ & $p$ & $r$ & $p$ & $r$ & $p$ \\
\hline RDI (events/h) & 0.028 & 0.782 & 0.083 & 0.407 & 0.107 & 0.284 & 0.08 & 0.42 \\
\hline T90 (\%) & 0.083 & 0.405 & 0.045 & 0.651 & 0.028 & 0.78 & 0.001 & 0.99 \\
\hline Sleep efficiency (\%) & 0.135 & 0.176 & 0.095 & 0.342 & 0.052 & 0.61 & 0.033 & 0.744 \\
\hline Lowest SpO2 (\%) & 0.001 & 0.992 & 0.029 & 0.773 & 0.044 & 0.659 & 0.013 & 0.899 \\
\hline ODI (dessaturations/h) & 0.056 & 0.577 & 0.024 & 0.81 & 0.053 & 0.592 & 0.029 & 0.77 \\
\hline
\end{tabular}

under PAP was confirmed in a recent meta-analysis. ${ }^{52}$ On the contrary, other studies ${ }^{29,35-37}$ reported that PAP therapy or mandibular advancement device ${ }^{37}$ did not influence Hcy levels in OSAS patients.

Previous studies suggest that OSAS is associated with dyslipidemia ${ }^{7}$ and type 2 diabetes. ${ }^{8}$ In fact, in this study dyslipidemia was more prevalent in OSAS patients comparing to snorers, although both groups showed similar glycemic and lipid profiles.

Indeed, some authors found that OSAS is independently associated with disorders of lipid metabolism, ${ }^{53}$ mainly due to intermittent hypoxia ${ }^{54}$ and sleep fragmentation. ${ }^{55}$ Furthermore, as in this study, triglycerides were associated with OSAS severity. ${ }^{53}$ This is an important issue once dyslipidemia is a major cause of atherosclerotic CVD. ${ }^{56}$

Moreover, severe OSAS showed a change in glycemic profile, even in absence of known diabetes, probably suggesting a pre-diabetic state, and it was correlated with sleep parameters (RDI and nocturnal desaturation). A condition characterized by insulin resistance and glucose intolerance is known as prediabetes. ${ }^{57}$ Individuals presenting this state are at risk of CVD and the majority will develop diabetes, ${ }^{58,59}$ putting our severe patients in an increased risk for both disorders. These results are in agreement with a meta-analysis which confirmed that moderate/severe OSAS increases the risk of development of type 2 diabetes, ${ }^{60}$ even following adjustment of obesity, age, co-morbidities, and medication use. ${ }^{61}$ Sleep fragmentation and intermittent hypoxia ${ }^{62}$ seem to be involved in carbohydrate dysregulation in OSAS, with impaired lipid metabolism, inflammation, oxidative stress and sympathetic nervous system activation. ${ }^{63}$

Concerning the evaluation of both profiles after PAP therapy, OSAS patients presented a statistical change in glycemic and lipid profiles, with a decrease in glucose, total and LDL cholesterol. Some trials provide evidence that PAP therapy may improve glucose metabolism ${ }^{64}$ especially in sleepy patients. ${ }^{65}$ However, other studies do not support this improvement, ${ }^{66}$ but the duration of treatment could be an explanation. A recent study has shown improvement in glucose metabolism with PAP therapy even in OSAS patients (overweight or obese) with prediabetes. ${ }^{67}$ Additionally, even in non-diabetic adults with OSAS, two meta-analyses have reported that PAP therapy modestly decreases HOMA-IR. ${ }^{68,69}$ Another study in diabetic OSAS patients has shown that one month of PAP therapy led to reduction of fasting glucose, $\mathrm{HbA} 1 \mathrm{C}$, and HOMA-IR, without change in BMI. ${ }^{70}$

A meta-analysis reported that PAP therapy decreases total cholesterol level, especially in OSAS patients who are younger, more obese, and who use PAP for a longer period ( $\geq 12$ weeks)..$^{71}$ However, in this meta-analysis PAP had no effect on fasting glucose or HOMA-IR. Also in a meta-regression analysis, PAP improved total and LDL cholesterol, with an increase in $\mathrm{HDL}$ cholesterol. ${ }^{7} \mathrm{~A}$ more recent meta-analysis ${ }^{72}$ reported that PAP significantly lowered total cholesterol, triglyceride, and HDL, but not LDL, particularly in moderate-severe patients, good compliance and daytime somnolence. However the magnitude of lipid reduction was modest and only significant in studies where autonomic hyperactivity was also lowered by PAP. In fact, in 


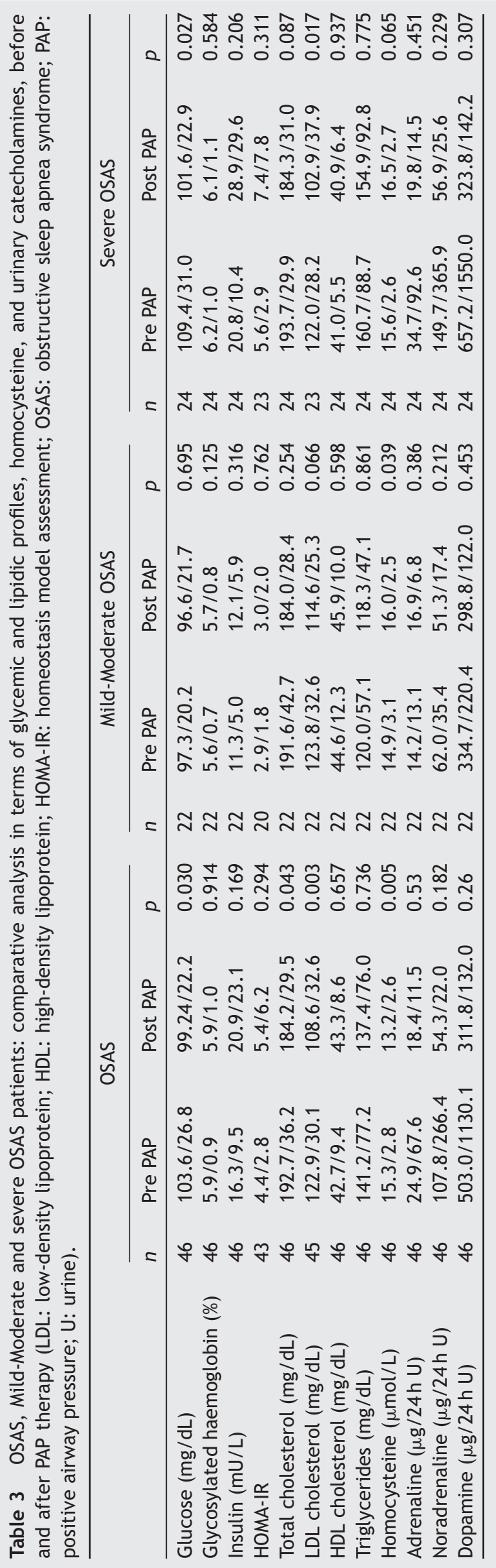

the present study OSAS patients presented a higher prevalence of dyslipidemia and after PAP there was a decrease in total and LDL cholesterol, without changing lifestyle habits. Moreover, urinary cathecolamines decrease to normal levels, however without statistical significance, which could have conditioned lipid lowering effect of PAP.

Treatment with PAP in OSAS may improve dyslipidemia through ameliorating hypoxia, inflammation, ${ }^{73}$ and insulin resistance. ${ }^{74}$ However, dyslipidemia in OSAS patients is far from being a simple process because, besides OSAS severity, several factors can contribute for it such as obesity, diet, and exercise. ${ }^{34,53,75,76}$ This fact and probably sample size could explain that the remainder of lipidic profile (triglyceride, total and HDL cholesterol) was not affected by PAP in this study.

This study showed a similar pattern of urinary catecholamines between snorers and OSAS patients and between OSAS patients of different severities. Additionally, in severe OSAS patients urinary catecholamines were higher than normal range. Although urinary cathecolamines were not correlated with sleep parameters, after six months of PAP, they decreased to normal levels, nonetheless without statistical significance. These results may be due to sample size because previous studies reported that in OSAS there is an increase in sympathetic activity, independently of obesity. ${ }^{77}$ In fact, Pinto et al. ${ }^{78}$ reported 24-h urinary norepinephrine levels significantly higher in severe OSAS than in mild-moderate, with a significant reduction after one month of PAP. Another study ${ }^{79}$ reported that PAP withdrawal resulted in rise in urinary noradrenaline and that was positively associated with hypoxaemia severity. Reduction of sympathetic activity can be a potential mediator of metabolic benefit from PAP (with improvement of glucose levels) as shown in a study by Pamidi et al. ${ }^{67}$

There are some limitations of this study, such as small sample size, female exclusion, and BMI differences between groups. Furthermore, drugs and diseases that interfere with vitamin B metabolism are potential causes for higher Hcy concentrations, ${ }^{80}$ and these vitamins were not determined in this study.

\section{Conclusion}

The present study demonstrated an association between glucose metabolism parameters and triglycerides with OSAS severity, contributing to the complexity of the process leading to cardiovascular/metabolic complications in this disorder. Moreover, Hcy, glycemic, and lipid profiles changed significantly after 6 months of PAP therapy in OSAS patients, supporting its cardiovascular and metabolic protective effect.

In conclusion, our study has reinforced the importance of analytical cardiovascular/metabolic evaluation as complementary tool of diagnosis/treatment response in OSAS patients.

\section{Ethical disclosures}

Protection of human and animal subjects. The authors declare that no experiments were performed on humans or animals for this study. 
Confidentiality of data. The authors declare that no patient data appear in this article.

Right to privacy and informed consent. The authors declare that no patient data appear in this article.

\section{Conflicts of interest}

The authors have no conflicts of interest to declare.

\section{References}

1. Eckert DJ, Malhotra A. Pathophysiology of adult obstructive sleep apnea. Proc Am Thorac Soc. 2008;5:144-53.

2. Franklin $\mathrm{K}$, Lindberg $\mathrm{E}$. Obstructive sleep apnea is a common disorder in the population - a review on the epidemiology of sleep apnea. J Thorac Dis. 2015;7:1311-22.

3. Martinez D, Klein C, Rahmeier L, da Silva RP, Fiori CZ, Cassol C, et al. Sleep apnea is a stronger predictor for coronary heart disease than traditional risk factors. Sleep Breath. 2012;16:695-701.

4. Macey PM, Kumar R, Woo MA, Yan-Go FL, Harper RM. Heart rate responses to autonomic challenges in obstructive sleep apnea. PLoS One. 2013;8:e76631.

5. Floras JS. Sleep apnea and cardiovascular risk. J Cardiol. 2014;63:3-8.

6. Ryan S, Crinion SJ, McNicholas WT. Obesity and sleep-disordered breathing when two 'bad guys' meet. QJM. 2014;107:949-54.

7. Nadeem R, Singh M, Nida M, Waheed I, Khan A, Ahmed S, et al. Effect of obstructive sleep apnea hypopnea syndrome on lipid profile: a meta regression analysis. J Clin Sleep Med. 2014; 10:475-89.

8. Pamidi S, Tasali E. Obstructive sleep apnea and type 2 diabetes: is there a link? Front Neurol. 2012;3:126.

9. Dempsey J, Veasey S, Morgan B, O’Donnell C. Pathophysiology of sleep apnea. Physiol Rev. 2010;90:47-112.

10. Lévy P, Ryan S, Oldenburg O, Parati G. Sleep apnoea and the heart. Eur Respir Rev. 2013;22:333-52.

11. Feng J, Zhang D, Chen B. Endothelial mechanisms of endothelial dysfunction in patients with obstructive sleep apnea. Sleep Breat. 2012;16:283-94.

12. Veeranna V, Zalawadiya SK, Niraj A, Pradhan J, Ference B, Burack RC, et al. Homocysteine and reclassification of cardiovascular disease risk. J Am Coll Cardiol. 2011;58:1025-33.

13. Faeh D, Chiolero A, Paccaud F. Homocysteine as a risk factor for cardiovascular disease: should we (still) worry about it? Swiss Med Wkly. 2006;136:745-56.

14. Loscalzo J, Handy DE. Epigenetic modifications: basic mechanisms and role in cardiovascular disease (2013 Grover Conference Series). Pulm Circ. 2014;4:169-74.

15. Bremner WF, Holmes EW, Kanabrocki EL, Hermida RC, Ayala D, Garbincius J, et al. Circadian rhythm of serum total homocysteine in men. Am J Cardiol. 2000;86:1153-6.

16. Xiao Y, Zhang Y, Lv X, Su D, Li D, Xia M, et al. Relationship between lipid profile and plasma total homocysteine, cysteine and the risk of coronary artery disease in coronary angiographic subjects. Lipid Health Dis. 2011;10:137.

17. Pang X, Liu J, Zhao J, Mao J, Zhang X, Feng L, et al. Homocysteine induces the expression of $\mathrm{C}$-reactive protein via NMDAr-ROS-MAPK-NF-KB signal pathway in rat vascular smooth muscle cells. Atherosclerosis. 2014;236:73-81.

18. Stanger O, Herrmann W, Pietrzik K, Fowler B, Geisel J, Dierkes $\mathrm{J}$, et al. Clinical use and rational management of homocysteine, folic acid, and B vitamins in cardiovascular and thrombotic diseases. Z Kardiol. 2004;93:439-53.
19. Girelli D, Martinelli N, Olivieri O, Pizzolo F, Friso S, Faccini $G$, et al. Hyperhomocysteinemia and mortality after coronary artery bypass grafting. PLoS One. 2006;1:e83.

20. Zhou YH, Tang JY, Wu MJ, Lu J, Wei X, Qin YY, et al. Effect of folic acid supplementation on cardiovascular outcomes: a systematic review and meta analysis. PLoS One. 2011;6:e25142.

21. Ford AH, Garrido GJ, Beer C, Lautenschlager NT, Arnolda $L$, Flicker $L$, et al. Homocysteine, grey matter and cognitive function in adults with cardiovascular disease. PLoS One. 2012; 7:e33345.

22. Okura T, Miyoshi K, Irita J, Enomoto D, Nagao T, Kukida M, et al. Hyperhomocysteinemia is one of the risk factors associated with cerebrovascular stiffness in hypertensive patients, especially elderly males. Naturecom Sci Rep. 2014;4:5663.

23. Shenov V, Mehendale V, Prabhu K, Shetty R, Rao P. Correlation of serum homocysteine levels with the severity of coronary artery disease. Ind J Clin Biochem. 2014;29:339-44.

24. Baszczuk A, Kopczynski Z. Hyperhomocysteinemia in patients with cardiovascular disease. Postepy Hig Med Dosw. 2014;68:579-89 [abstract].

25. Zhang S, Yong-Yi B, Luo LM, Xiao WK, Wu HM, Ye P. Association between serum homocysteine and arterial stiffness in elderly: a community-based study. J Geriatr Cardiol. 2014;11:32-8.

26. Lentz SR. Mechanisms of homocysteine induced atherothrombosis. J Thromb Haemost. 2005;3:1646-54.

27. Lavie L, Perelman A, Lavie P. Plasma homocysteine levels in obstructive sleep apnea - association with cardiovascular morbidity. Chest. 2001;120:900-8.

28. Lavie L. Obstructive sleep apnoea syndrome: an oxidative stress disorder. Sleep Med Rev. 2003;7:35-51.

29. Svatikova A, Wolk R, Magera MJ, Shamsuzzaman AS, Phillips BG, Somers VK. Plasma homocystein in obstructive sleep apnea. Eur Heart J. 2004;25:1325-9.

30. Ersoy EO, Fırat H, Akaydın S, Özkan Y, Durusu M, Yüce GD, et al. Association of obstructive sleep apnea with homocystein, nitric oxide and total antioxidant capacity levels in patients with or without coronary artery disease. Tuberk Toraks. 2014;62:207-14.

31. Can M, Açikgöz S, Mungan G, Bayraktaroğlu T, Koçak E, Güven $B$, et al. Serum cardiovascular risk factors in obstructive sleep apnea. Chest. 2006;129:233-7.

32. Kokturk O, Ciftci TU, Mollarecep E, Ciftci B. Serum homocysteine levels and cardiovascular morbidity in obstructive sleep apnea syndrome. Resp Med. 2006;100:536-41.

33. Jordan W, Berger C, Cohrs S, Rodenbeck A, Mayer G, Niedmann $P D$, et al. CPAP-therapy effectively lowers serum homocysteine in obstructive sleep apnea syndrome. J Neural Transm. 2004;111:683-9.

34. Robinson GV, Pepperell JCT, Segal HC, Davies RJO, Stradling JR. Circulating cardiovascular risk factors in obstructive sleep apnoea: data from randomised controlled trials. Thorax. 2004;59:777-82

35. Barceló A, Barbé F, de la Peña M, Vila M, Pérez G, Piérola J, et al. Antioxidant status in patients with sleep apnoea and impact of continuous positive airway pressure treatment. Eur Respir J. 2006;27:756-60.

36. Ryan S, Nolan GM, Hannigan E, Cunningham S, Taylor C, McNicholas WT. Cardiovascular risk markers in obstructive sleep apnoea syndrome and correlation with obesity. Thorax. 2007;62:509-14.

37. Dal-Fabbro C, Garbuio S, D'Almeida V, Cintra F, Tufik S, Bittencourt L. Mandibular advancement device and CPAP upon cardiovascular parameters in OSA. Sleep Breath. 2014;18: 749-59.

38. Berry RB, Budhiraja R, Gottlieb DJ, Gozal D, Iber C, Kapur $V K$, et al. Rules for scoring respiratory events in sleep: update of the 2007 AASM Manual for Scoring of Sleep and Associated Events Deliberations of the Sleep Apnea Definitions Task Force 
of the American Academy of Sleep Medicine. J Clin Sleep Med. 2012;8:597-619.

39. Qaseem A, Holty J-E, Owens D, Dallas P, Starkey M, Shekelle P. The Clinical Guidelines Committee of the American College of Physicians Management of Obstructive Sleep Apnea in Adults: a clinical practice guideline from the American College of Physicians. Ann Intern Med. 2013;159:471-83.

40. Wallace TM, Levy JC, Matthews DR. Use and abuse of HOMA modeling. Diab Care. 2004;27:1487-95.

41. Weaver TE, Sawyer AM. Adherence to continuous positive airway pressure treatment for obstructive sleep apnea: implications for future interventions. Indian J Med Res. 2010;131:245-58.

42. Fung TT, Rimm EB, Spiegelman D, Rifai N, Tofler GH, Willett WCD, et al. Association between dietary patterns and plasma biomarkers of obesity and cardiovascular disease risk. Am J Clin Nutr. 2001;73:61-7.

43. De Pergola G, Pannacciulli N, Zamboni M, Minenna A, Brocco G, Sciaraffia M, et al. Homocysteine plasma levels are independently associated with insulin resistance in normal weight, overweight and obese pre-menopausal women. Diabetes Nutr Metab. 2001;14:253-8.

44. Sanchez-Margalet V, Valle M, Ruz FJ, Gascon F, Mateo J, Goberna R. Elevated plasma total homocysteine levels in hyperinsulinemic obese subjects. J Nutr Biochem. 2002;13:75-9.

45. Konukoğlu D, Serin O, Ercan M, Turhan MS. Plasma homocysteine levels in obese and non-obese subjects with or without hypertension; its relationship with oxidative stress and copper. Clin Biochem. 2003;36:405-8.

46. Bazzano LA, He J, Muntner P, Vupputuri S, Whelton PK. Relationship between cigarette smoking and novel risk factors for cardiovascular disease in the United States. Ann Intern Med. 2003;138:891-7.

47. Sobczak A, Wardas W, Zielinska-Danch W, Pawlicki K. The influence of smoking on plasma homocysteine and cysteine levels in passive and active smokers. Clin Chem Lab Med. 2004;42:408-14.

48. Slater G, Pengo M, Kosky C, Steier J. Obesity as an independent predictor of subjective excessive daytime sleepiness. Respir Med. 2013;107:305-9.

49. Niu X, Chen X, Xiao Y, Dong J, Zhang $R$, Lu M, et al. The differences in homocysteine level between obstructive sleep apnea patients and controls: a meta-analysis. PLoS One. 2014;9:e95794.

50. Chen M, Wu B, Ye X, Zhou Z, Yue X, Wang W, et al. Association between plasma homocysteine levels and obstructive sleep apnoea in patients with ischaemic stroke. J Clin Neurosci. 2011;18:1454-7.

51. Sales LV, Bruin VM, D’Almeida V, Pompéia S, Bueno OF, Tufik S, et al. Cognition and biomarkers of oxidative stress in obstructive sleep apnea. Clinics (Sao Paulo). 2013;68:449-55.

52. Chen X, Niu X, Xiao Y, Dong J, Zhang R, Lu M, et al. Effect of continuous positive airway pressure on homocysteine levels in patients with obstructive sleep apnea: a meta-analysis. Sleep Breath. 2014;18:687-94.

53. Toyama Y, Chin K, Chihara Y, Takegami M, Takahashi K, Sumi $\mathrm{K}$, et al. Association between sleep apnea, sleep duration, and serum lipid profile in an urban, male, working population in Japan. Chest. 2013;143:720-8.

54. Dewan NA, Nieto FJ, Somers VK. Intermittent hypoxemia and OSA: implications for comorbidities. Chest. 2015;147:266-74.

55. Qian Y, Yi H, Zou J, Meng L, Tang X, Zhu H, et al. Independent association between sleep fragmentation and dyslipidemia in patients with obstructive sleep apnea. Scient Rep. 2016;6:26089.

56. Graham I, Cooney MT, Bradley D, Dudina A, Reiner Z. Dyslipidemias in the prevention of cardiovascular disease: risks and causality. Curr Cardiol Rep. 2012;14:709-20.
57. Centers for Disease Control and Prevention. National diabetes fact sheet: national estimates and general information on diabetes and prediabetes in the United States, 2011. Atlanta, GA: US Department of Health and Human Services, Centers for Disease Control and Prevention; 2011.

58. Nathan DM, Davidson MB, De Fronzo RA, Heine RJ, Henry RR, Pratley R, et al. American Diabetes Association impaired fasting glucose and impaired glucose tolerance: implications for care. Diab Care. 2007;30:753-9.

59. De Fronzo RA, Abdul-Ghani M. Assessment and treatment of cardiovascular risk in prediabetes: impaired glucose tolerance and impaired fasting glucose. Am J Cardiol. 2011;108 Suppl.:3B-24B.

60. Wang X, Bi Y, Zhang Q, Pan F. Obstructive sleep apnoea and the risk of type 2 diabetes: a meta-analysis of prospective cohort studies. Respirology. 2013;18:140-6.

61. Kent BD, Grote L, Ryan S, Pépin JL, Bonsignore MR, Tkacova $\mathrm{R}$, et al. Diabetes mellitus prevalence and control in sleepdisordered breathing: the european sleep apnea cohort (ESADA) study. Chest. 2014;146:982-90.

62. Borel AL, Monneret D, Tamisier R, Baguet JP, Faure P, Levy P, et al. The severity of nocturnal hypoxia but not abdominal adiposity is associated with insulin resistance in non-obese men with sleep apnea. PLoS One. 2013;8:e71000.

63. Briançon-Marjollet A, Weiszenstein M, Henri M, Thomas A, Godin-Ribuot D, Polak J. The impact of sleep disorders on glucose metabolism: endocrine and molecular mechanisms. Diabetol Metabol Synd. 2015;7:25.

64. Steiropoulos P, Papanas N, Nena E, Tsara V, Fitili C, Tzouvelekis $A$, et al. Markers of glycemic control and insulin resistance in non-diabetic patients with obstructive sleep apnea hypopnea syndrome: does adherence to CPAP treatment improve glycemic control? Sleep Med. 2009;10:887-91.

65. Weinstock TG, Wang X, Rueschman M, Ismail-Beigi F, Aylor J, Babineau DC, et al. A controlled trial of CPAP therapy on metabolic control in individuals with impaired glucose tolerance and sleep apnea. Sleep. 2012;35:25B-617B.

66. Hecht L, Mohler R, Meyer G. Effects of CPAP-respiration on markers of glucose metabolism in patients with obstructive sleep apnoea syndrome: a systematic review and meta-analysis. Ger Med Sci. 2011;9:Doc20.

67. Pamidi S, Wroblewski K, Stepien M, Sharif-Sidi K, Kilkus J, Whitmore $\mathrm{H}$, et al. Eight hours of nightly continuous positive airway pressure treatment of obstructive sleep apnea improves glucose metabolism in patients with prediabetes. A randomized controlled trial. Am J Respir Crit Care Med. 2015;192:96-105.

68. Iftikhar IH, Khan MF, Das A, Magalang UJ. Meta-analysis: continuous positive airway pressure improves insulin resistance in patients with sleep apnea without diabetes. Ann Am Thorac Soc. 2013;10:115-20.

69. Yang D, Liu Z, Yang H, Luo Q. Effects of continuous positive airway pressure on glycemic control and insulin resistance in patients with obstructive sleep apnea: a meta-analysis. Sleep Breath. 2013;17:33-8.

70. Guo LX, Zhao X, Pan Q, Sun X, Li H, Wang XX, et al. Effect of continuous positive airway pressure therapy on glycemic excursions and insulin sensitivity in patients with obstructive sleep apnea-hypopnea syndrome and type 2 diabetes. Chin Med J. 2015;128:2301-6.

71. Xu H, Yi H, Guan J, Yin S. Effect of continuous positive airway pressure on lipid profile in patients with obstructive sleep apnea syndrome: a meta-analysis of randomized controlled trials. Atherosclerosis. 2014;234:446-53.

72. Lin MT, Lin HH, Lee PL, Weng PH, Lee CC, Lai TC, et al. Beneficial effect of continuous positive airway pressure on lipid profiles in obstructive sleep apnea: a meta-analysis. Sleep Breath. 2015;19:809-17. 
73. Cholidou KG, Kostakis ID, Manali ED, Perrea D, Margeli A, Vougas K, et al. Calprotectin: a protein related to cardiovascular risk in adult patients with obstructive sleep apnea. Cytokine. 2013;61:917-23.

74. Buechner NJ, Zidek W, Eer M, Haske M, Sanner BM. Obstruc tive sleep apnea syndrome. Effects of therapy on dyslipidemia. Somnologie. 2001;5:97-102.

75. Trzepizur W, Le Vaillant M, Meslier N, Pigeanne T, Masson P, Humeau MP, et al. Independent association between nocturnal intermittent hypoxemia and metabolic dyslipidemia. Chest. 2013;143:1584-9.

76. Ip MS, Lam KS, Ho C, Tsang KW, Lam W. Serum leptin and vascular risk factors in obstructive sleep apnea. Chest. 2000;118:580-6.

77. Grassi G, Facchini A, Trevano FQ, Dell'Oro R, Arenare F, Tana F, et al. Obstructive sleep apnea-dependent and -independent adrenergic activation in obesity. Hypertension. 2005;46:321-5.
78. Pinto P, Bárbara C, Montserrat J, Patarrão R, Guarino M, Carmo $M$, et al. Effects of CPAP on nitrate and norepinephrine levels in severe and mild-moderate sleep apnea. BMC Pulm Med. 2013;13:13.

79. Phillips C, Yang Q, Williams A, Roth M, Yee B, Hedner J, et al. The effect of short-term withdrawal from continuous positive airway pressure therapy on sympathetic activity and markers of vascular inflammation in subjects with obstructive sleep apnoea. J Sleep Res. 2007; 16:217-25.

80. Curro M, Gugliandolo A, Gangemi C, Risitano R, Lentile $R$, Caccamo D. Toxic effects of mildly elevated homocysteine concentrations in neuronal-like cells. Neurochem Res. 2014;39:1485-95. 